\title{
O problema do saber na adolescência e o real da puberdade
}

\author{
Daniela Teixeira Dutra Viola* \\ Ângela Maria Resende Vorcaro \\ Universidade Federal de Minas Gerais, Departamento de Psicologia, Belo Horizonte, MG, Brasil
}

Resumo: 0 presente artigo propõe uma reflexão sobre o tema da adolescência na Psicanálise a partir de um recorte que privilegia a articulação entre o saber, com suas múltiplas implicações, e a puberdade, como o real do corpo que irrompe nesse momento da vida. Apresentaremos pontos das obras de Freud e de Lacan que corroboram essa articulação, bem como algumas discussões de autores contemporâneos que tangenciam essa problemática.

Palavras-chave: adolescência, puberdade, saber, objeto.

\section{A adolescência e a Psicanálise}

Embora não seja um conceito da Psicanálise, a adolescência é um tema de grande importância para a práxis psicanalítica, na medida em que sua transição acarreta implicações fundamentais para o sujeito e para o laço social. Mesmo que não trate especificamente da adolescência, em diversos momentos de sua obra Freud aborda a puberdade, evento orgânico que faz o sujeito adolescer. Da obra freudiana, passando pelos autores pós-freudianos e pelo ensino lacaniano, até os autores contemporâneos do campo psicanalítico, muitos se debruçam sobre esse tempo de travessia. A adolescência, efeito da puberdade, é instigante, provocativa e embaraçosa. Condição subjetiva de amplo impacto na sociedade e na cultura, ela incorpora, coletivamente, certos sintomas de seu tempo. A incidência da violência e da subversão nesse período, que se caracteriza por uma "crise", denuncia o parentesco entre a puberdade e o trauma, a ruptura.

Na contemporaneidade, diante de importantes modificações na estrutura familiar, na trama simbólica de referenciais e na figura de autoridade paterna, a complexidade da transição da puberdade é potencializada. Além disso, o amplo e irrestrito acesso à informação, a erotização cada vez mais precoce da criança por causa da mídia e a abrangência cada vez mais extensa das vivências cibernéticas nos obrigam a relativizar a noção de latência, período que antecede a puberdade, tal como teorizada por Freud.

Tendo tudo isso em vista, é preciso considerar que o sujeito adolescente, necessariamente desamparado diante do real da puberdade, não é mais o mesmo. Vivemos na época da oferta generalizada de gozo e de objetos descartáveis, da crescente fragilização dos referenciais e dos enlaces socioafetivos. Perante a gravidade das respostas que têm se apresentado, torna-se cada vez mais premente a compreensão do que está em jogo nesse tempo do sujeito.

* Autora correspondente: daniela.dutraviola@gmail.com
Reconhecendo os impasses da "crise adolescente" na contemporaneidade, recorremos à práxis psicanalítica a fim de delinear um eixo teórico orientador para a clínica com adolescentes. O arcabouço teórico da Psicanálise nos oferece uma extensa literatura sobre esse tema desde a obra Três ensaios sobre a teoria da sexualidade (Freud, 1905/1996a). Mesmo antes da publicação dessa obra, o objeto original da pesquisa de Freud é a etiologia sexual das neuroses, e sua investigação se baseia em diversos casos de adolescentes, em que a neurose foi deflagrada em torno da puberdade. Conquanto tenha havido, nessas histórias clínicas, sintomas infantis, é notório que na adolescência algo novo se apresenta. Pode-se considerar que a própria clínica psicanalítica é inaugurada em meio ao mal-estar que envolve a adolescência.

Embora o terceiro dos três ensaios sobre a teoria da sexualidade seja uma referência clássica sobre a puberdade, ele não encerra o pensamento de Freud sobre o tema, que está difundido ao longo de toda a sua produção teórica. De maneira bastante sucinta, podemos destacar três aspectos principais na obra de Freud relacionada à puberdade: a importância fundamental dos fatores orgânicos na determinação dos aspectos psíquicos, o caráter delicado e complexo desse período e o papel essencial da fantasia inconsciente, estreitamente relacionada aos processos sublimatórios e à pulsão epistemológica, elementos definidores da latência.

Compreendemos que Freud apresenta uma formulação condensadora de sua perspectiva de puberdade por meio da proposição de que nesse período ocorre o "encontro do objeto" (Freud, 1905/1996a). Mais precisamente, "o reencontro do objeto", uma vez que este remete metonimicamente ao primeiro objeto de desejo, o seio materno. Essa concepção dialética da puberdade como um reencontro do primeiro objeto enlaça os três aspectos mencionados: a importância do real do corpo em jogo, a complexidade dos processos envolvidos e o papel crucial da fantasia inconsciente e da latência como operadoras da lacuna entre os dois tempos da sexualidade, separando o "encontro" do "reencontro". 
Lacan, por sua vez, não trata especificamente da puberdade. No entanto, o tema aparece em alguns momentos pontuais da obra lacaniana. Podemos ressaltar a releitura dos Três ensaios de Freud, que tem como ponto de partida Os complexos familiares na formação do indivíduo, de 1938. Nesse trabalho, ao examinar o "complexo de Édipo", o autor comenta que se este marca o auge da sexualidade infantil, também é o operador da redução de suas imagens ao estado de latência, momento de sublimação, anterior à puberdade (Lacan, 1938/2003a).

No Seminário 4, A relação de objeto (Lacan, 1956-1957/1995), o autor volta a enfatizar a bipartição do desenvolvimento da sexualidade humana, separada em dois tempos por uma lacuna, que seria responsável pela "memória latente" do primeiro objeto, a mãe, a ser posteriormente reencontrado. Para ele, esta é a primeira dialética freudiana da sexualidade, base sobre a qual se apoia a teoria da puberdade expressa nos Três ensaios. Ainda nessa releitura do complexo de Édipo, Lacan propõe os três tempos desse complexo, no Seminário 5, As formações do inconsciente (1957-1958/1999). Nesse seminário, destaca-se a importância do "ideal do eu" como saída identificatória do Édipo, e a ideia de que tudo que é definido com o complexo edipiano pode ser contestado, revisado e deslocado na puberdade.

Como referência ulterior sobre a puberdade, há o escrito "Prefácio a $O$ despertar da primavera" (Lacan, 1974/2003b), a peça do dramaturgo alemão Frank Wedekind (1891/1973). Nesse comentário sobre uma obra literária, Lacan apresenta uma abordagem atualizada da puberdade, inspirada pelas reflexões daquele período de sua obra, tais como as relações entre o gozo e o sentido e a formalização da tese "não há relação sexual". Do "Prefácio", salientamos a ideia de que o encontro sexual na puberdade é sempre mal sucedido, e que Wedekind, quanto a isso, em sua ficção, antecipa Freud. Para delinear o real em jogo na puberdade, Lacan se vale da imagem do furo e do desvelamento. A sexualidade faz um furo no real, algo a que todos estão sujeitos. Como descrição desse furo, dessa entrada em cena da sexualidade de maneira abrupta no drama pessoal de cada adolescente, o autor afirma que, na cena privada, o púbis torna-se público, exibe-se como objeto de uma levantada de véu, ainda que um véu que não mostre nada.

Esses momentos da obra de Lacan são geralmente assinalados como pontos de esclarecimento de uma possível abordagem lacaniana da puberdade. Entre esses dois extremos - a elaboração ainda na década de 1950, no auge da releitura exegética de Freud e da construção de um estruturalismo lacaniano, e, do outro lado, um escrito mais tardio, já da década de 1970, no apogeu da formalização topológica e da preponderância do gozo como termo essencial para a práxis - encontramos um momento intermediário do qual podemos extrair um desenvolvimento teórico sobre o tema da puberdade. Partimos de uma menção à puberdade encontrada no Seminário 10, A angústia (Lacan, 1962-1963/2005):
Há milhares de indícios sensíveis de que o momento em que realmente começa o funcionamento do conceito ... poderia ser situado de maneira totalmente diversa, em função de um vínculo a ser estabelecido entre a maturação do objeto $a$, tal como eu o defino, e a idade da puberdade. (Lacan, 1962$1963 / 2005$, p. 282)

Trata-se de uma passagem obscura desse seminário de Lacan, em um momento teórico de formulação e desenvolvimento da noção de objeto $a$, operador teórico essencial do ensino lacaniano. Essa menção à puberdade não é repercutida nas aulas posteriores, restando como um ponto de enigma nesse contexto. Voltaremos a essa passagem, mas, por ora, recorremos a Freud e sua concepção de latência.

\section{A latência, prelúdio da puberdade}

Freud (1905/1996a) apresenta uma discussão bem descritiva dos eventos biológicos que detonam a puberdade. Para ele, está claro que o real em jogo é preponderante em todos os acontecimentos que caracterizam a passagem adolescente, e esse evento do real está atrelado ao que ele designa como "encontro do objeto". No presente trabalho, defendemos a hipótese de que essa formulação está relacionada a uma articulação constitutiva entre o saber e o real em jogo na puberdade. Para compreendermos essa articulação, é necessário focalizar o período que antecede a puberdade, a latência.

Para Freud (1905/1996a; 1911/1996d), no período da latência a pulsão sexual é desviada para outras finalidades, tais como a construção de aspirações estéticas e morais e a aquisição de conhecimento. Ao mesmo tempo em que a sublimação opera no fomento da assimilação de saberes transmissíveis - o que Freud relaciona à pulsão de saber, calcada na curiosidade sexual - a fantasia se fortalece no inconsciente (Freud, 1911/1996d). O saber transmissível, ao qual se relaciona o conhecimento, os conceitos, o que se aprende pela educação, não se confunde com o saber inconsciente, desvelado pela hipótese freudiana. Contudo, essas duas formas do saber estão radicalmente entrelaçadas, como se percebe a partir da concepção do período de latência, quando a sublimação e a fantasia inconsciente têm papéis cruciais. Pulsão de saber e pulsão sexual são as duas faces de um mesmo movimento pulsional, que resulta tanto nos produtos sublimatórios - o conhecimento científico, a arte, o trabalho - como na fantasia.

Freud (1905/1996a) postula a sexualidade humana instaurada em dois tempos separados. No primeiro, a criança pequena vivencia o autoerotismo e o complexo de Édipo, com predomínio das pulsões parciais. O segundo tempo é marcado pelo despertar da pulsão sexual, que retorna vigorosa sobre o jovem púbere, recém-saído da infância, às voltas com um corpo estranho, acometido pela libido de uma nova maneira. Entre eles, há um longo período de latência, a hibernação da pulsão sexual.

Para Freud (1924/1996i), o que propicia a latência é a dissolução do complexo de Édipo, precipitada, no final 
da primeira infância, pelos efeitos de sua impossibilidade e pelo medo da castração. Na fase fálica do Édipo, a criança experimenta um conflito entre seu interesse narcísico pelo falo e o investimento libidinal em seus objetos parentais. Com a ameaça de castração, "triunfa normalmente a primeira dessas forças" (p. 196), ou seja, o Édipo declina para resguardar o falo. Esse processo ocorre através de uma substituição do investimento no par parental por identificações, constituindo o supereu a partir da introjeção da autoridade paterna.

Percebe-se que a latência, embora relacionada a um período de "calmaria", de certa dormência pulsional, é, porém, inaugurada por um intenso conflito, sob a lâmina da angústia de castração. Trata-se de uma calmaria apenas na superfície, que encobre as águas tortuosas de uma angústia pungente e de um supereu em construção. Sobre o supereu, Freud sublinha que não é simplesmente um resíduo das primitivas escolhas objetais do isso, mas uma formação reativa enérgica contra tais escolhas, demarcando seu caráter imperativo e feroz. Em sua origem estão, principalmente, dois fatores: a duração prolongada, no ser humano, do desamparo e da dependência de sua infância e o início bifásico da sua vida sexual (Freud, 1923/1996g).

Em Inibições, sintomas e ansiedade (Freud, 1926/1996j), é explícito quanto às tormentas da latência ao associá-la a "situações de perigo antigas", deflagradoras da angústia. Como no contexto de sua discussão sobre o supereu, em $O$ eи e o isso (1923/1996g), faz alusão ao "mito da era glacial" - no qual as adversidades naturais extremas teriam propiciado as condições subjetivas iniciais da humanidade. É significativa para a compreensão da latência a hipótese de que "algo momentoso deve ter ocorrido nas vicissitudes da espécie humana que deixou para trás essa interrupção no desenvolvimento sexual do indivíduo como um precipitado histórico" (Freud, 1926/1996j, p. 151). Mesmo que mítica, trata-se de uma associação importante entre essa lacuna temporal e a constituição de algo fundamental do ser humano.

Para entender essa função constitutiva da latência, lembremos a relação radical entre esse período e a fantasia. Como ensina Freud (1919/1996f), a cena da fantasia é uma cena de violência, cujo caráter perverso se deve à prematuridade da sexualidade humana e à interrupção da latência, que afasta o componente sexual propriamente infantil do restante da vida sexual, aflorado a partir da puberdade. Nesse meio tempo, em decorrência do recalque, algo se fixa sob a forma de uma cena. Sendo assim, na latência não apenas se processa a sublimação, com o desvio da pulsão para fins "mais elevados", que Freud relaciona aos mais diversos saberes, manifestos, necessários à civilização, como também se fortalece a fantasia, que pode ser pensada como uma formulação de saber, um saber a respeito do objeto, um saber latente sobre o gozo.

Nesse sentido, se, por um lado, a angústia de castração funda a latência, por outro, ela sinaliza o objeto em cena, na fantasia. Freud compreende a angústia na infância como sinal de um perigo pulsional. Quando "começa o processo de encontrar um objeto, ele é logo interrompido pelo longo período de latência que retarda o desenvolvimento sexual até a puberdade" (Freud, 1911/1996d, p. 241). Esse processo conduz a uma vinculação mais estreita entre a pulsão sexual e a fantasia. Em outras palavras, se, na latência, o objeto não chega a entrar em cena para o sujeito, na fantasia ele é protagonista, daí a relação fundamental entre a latência e a fantasia. E é a fantasia, a encenação do objeto, que fomenta toda a riqueza sublimatória que acompanha e caracteriza a latência.

\section{Adolescência e saber: um engajamento no corpo}

Voltando ao comentário de Lacan sobre a puberdade e o conceito, é importante lembrar que o Seminário 10 é aquele em que o problema da corporeidade, do corpo como organismo, do real orgânico, é levado às últimas consequências, no percurso que conduz do exame de um afeto, a angústia, à postulação de um elemento lógico fundamental, o objeto $a$, proposto, de início, como um resto análogo aos apêndices desprendidos do corpo, restos de operações de corte. É, portanto, considerando essa tonalidade "naturalista" desse seminário que devemos ler o termo "maturação", um termo tomado da biologia, que nessa passagem aparece como articulador da puberdade ao objeto $a$. Nesse mesmo sentido, é necessário acrescentar que o Seminário 10 se localiza em um momento de transição do próprio ensino lacaniano, na passagem da preponderância do conceito de desejo para o conceito de gozo. E o objeto $a$ tem um papel protagonista nessa passagem, visto que possibilita a articulação entre o desejo e o gozo. ${ }^{1}$

A postulação do objeto $a$ é de grande importância para o entendimento da puberdade, na medida em que possibilita uma nova leitura do tema dos "estágios de desenvolvimento sexual", bem como da relação destes com a angústia de castração. Freud propõe "as fases do desenvolvimento da organização sexual": oral, sádico-anal, período de latência e puberdade (Freud, 1905/1996a). No artigo "A organização genital infantil" (Freud, 1923/1996h), faz um acréscimo fundamental a essa lista: a fase fálica, em que o único órgão genital reconhecido por meninas e meninos é o pênis. E é a partir desse adendo que pode desenvolver, com todas as suas implicações, a teoria da castração. Por mais que ele tente estabelecer uma temporalidade cronológica

\footnotetext{
1 Sobre o caráter "naturalista" do Seminário 10, Jacques-Alain Miller (2005) aponta que, nesse momento de formulação do objeto $a$, Lacan busca aprimorar o contorno do real pela via de um afeto, a angústia. Para ele, a abordagem da angústia possibilita que o gozo se libere da amarração significante de sua prisão fálica, dado que a angústia sinaliza os pontos de incidência do gozo no corpo sob a forma dos objetos $a$. Ele enfatiza que o corpo imaginário, tal como é concebido pela teoria do estádio do espelho, dá lugar a um corpo real, orgânico. O corpo passa a ser examinado de uma forma muito mais ampla, em sua dimensão visceral, em todas as suas partes, órgãos e funções. Christian Dunker (2006) também chama a atenção para essa característica do Seminário 10. De acordo com ele, esse curso corresponde a um segundo momento teórico das relações de Lacan com o tema da corporeidade, sendo o primeiro a concepção do estádio do espelho e o terceiro a teoria da sexuação.
} 
guiada pela evolução orgânica, isso não se concretiza. Sua própria teorização apresenta contradições e o principal contraponto provém da teoria da latência, da constituição da sexualidade em dois tempos separados, o que possibilita a intuição de um movimento retroativo.

Lacan nos oferece importantes considerações a respeito dos "estágios", da temporalidade na constituição subjetiva. Em sua abordagem da angústia (Lacan, 19621963/2005), ele propõe que esse afeto irrompe na presença do objeto $a$, formulado como resto da constituição subjetiva, um vazio relacionado ao campo do gozo que entra em cena em cada tempo lógico da subjetivação. Em uma releitura das fases e objetos parciais propostos por Freud, Lacan postula que o objeto $a$ é o referente lógico que está em jogo no encadeamento dos estágios, nas formas dos "objetos cedíveis". Essa teorização permite uma retomada da questão dos estágios constitutivos do sujeito sob a ótica de uma lógica, e não de uma cronologia, o que é de grande relevância na compreensão da puberdade. Édipo, latência e puberdade passam a ser pensados, portanto, em uma temporalidade lógica, subjetiva, inerente ao sujeito.

A linguagem deixa marcas no sujeito, marcas no corpo, sob a forma do traumatismo. O trauma, em última instância, é a entrada na linguagem, e o objeto $a$, como resto que ficou de fora, tem essa característica ambígua de mediação entre os registros real, simbólico e imaginário. Assim, o objeto $a$ é o operador de um "engajamento no corpo" pelo significante, e a constituição do sujeito pela via do traumatismo - da entrada na linguagem e do encontro com o real da sexualidade - tem função organizadora no corpo, que, de outra maneira, sucumbe à dispersão e ao caos.

Essa função organizadora decorre da angústia de castração, motor de um movimento retroativo, efeito da incidência do objeto $a$ em cada "estágio". Ao se deparar com o real da castração, o sujeito é reenviado, retroativamente, a cada uma das etapas em que um dos objetos cedíveis deixou sua marca. Com esse movimento retroativo, cada um desses objetos é atravessado pelo vazio da castração. Nesse movimento, algo da contingência, um evento que remete o sujeito à castração, retorna e dá sentido à sucessão temporal. E esse evento contingente pode ser localizado na puberdade, no encontro com o real da sexualidade, visto que nesse período toda a ordenação da sexualidade pode se modificar.

Além do objeto $a$, o outro elemento crucial nessa contextualização é o debate em que Lacan está implicado no momento em que menciona a puberdade no Seminário 10. Na lição focalizada, ele está às voltas com o problema do ensino da Psicanálise, da transmissão dos conceitos. Além disso, ele explicita que está de acordo com a ideia de que só há verdadeiro acesso aos conceitos a partir da puberdade, que a "maturação do objeto $a$ " nesse período tem uma conexão com o início do "funcionamento do conceito" (Lacan, 1962-1963/2005). Quanto à concepção lacaniana de "conceito", há uma definição pontual em uma lição posterior à que acabamos de mencionar: atingir o conceito, segundo Lacan, é poder apreender o real por um significante que comanda esse real de acordo com sua causação íntima (p. 323).

Um debate com a educação e com a psicologia do desenvolvimento aparece em alguns outros meandros do Seminário 10. Lacan reitera que é "precisamente o desejo que move a função do conhecimento" (Lacan, 1962$1963 / 2005$, p. 239), de maneira que o objeto $a$, em sua dimensão de "causa do desejo", tem um papel pivô na problemática do conhecimento, isto é, a causa "sempre surge em correlação com o fato de que algo é posto em consideração no conhecimento" (p. 239). O autor afirma que essa reflexão implica "um questionamento mais radical do que jamais se articulou, em nossa filosofia ocidental, da função do conhecimento" (p. 241).

Nessa mesma linha de pensamento, Lacan indaga sobre a natureza do conhecimento que existe na fantasia, concluindo que o sujeito, a partir do momento em que fala, já está implicado por essa fala em seu corpo, e que, portanto, a raiz do conhecimento é esse "engajamento no corpo" (Lacan, 1963/2005, p. 241).

O exemplo mais notório de uma interlocução com a educação e com a psicologia do desenvolvimento no contexto tratado é a extensa elaboração acerca da "torneira de Piaget". Lacan comenta a concepção piagetiana de aquisição da linguagem por meio da análise de algumas ideias extraídas do livro A linguagem e o pensamento na criança (Piaget, 1923/1999), no qual é descrito o experimento com a torneira (Lacan, 1962-1963/2005). No entendimento lacaniano, o erro de Piaget reside na crença de que a fala tem como efeito a comunicação, quando "o efeito do significante é fazer surgir no sujeito a dimensão do significado" (p. 311). Nesse experimento, o experimentador dá à criança uma breve explicação sobre o funcionamento de uma torneira, dividida esquematicamente em partes, e essa criança tem que repetir essa explicação ao experimentador e depois transmitir essa explicação a outra criança. Piaget se surpreende com a diferença entre uma e outra narração, pois a primeira criança demonstra, ao experimentador, ter apreendido perfeitamente bem a explicação, mas em seguida a segunda criança não reproduz bem esse relato, demonstrando não ter compreendido o funcionamento da torneira a partir do relato da primeira.

Lacan levanta várias questões sobre esse experimento. Ele observa que há um desinteresse da segunda criança pelos mecanismos subjacentes à torneira. Para Lacan, o que de fato interessa à criança é que a torneira serve para fechar a água. E, graças a isso, é possível encher uma bacia sem que ela transborde. Nessa simples relação da torneira com seu efeito, situa-se a dimensão de causa, que tem como efeito o represamento da água, relação de causa e efeito que lastreia a cadeia significante em jogo para a criança. Conforme Lacan, Piaget desconhece o que há de interessante para uma criança em uma torneira, a saber, os desejos despertados pela torneira, como, por exemplo, de urinar.

De acordo com Jésus Santiago (2010), Lacan lança mão dessas observações experimentais de Piaget sobre a 
passagem, na criança, da "linguagem egocêntrica" para a "linguagem socializada" para demonstrar que no lugar da estrutura de intencionalidade, deve ser apreendida a estrutura de causalidade, na medida em que o objeto passa a ser compreendido como o que está "por trás" do desejo, como causa. Santiago considera que Lacan interpreta Piaget ao afirmar que se este não pode captar o que está em jogo para a criança em relação à torneira, ou seja, sua função de causa, isso se explica porque Piaget nada sabe sobre a libido, sobre o gozo, sobre o modo como a causa opera na subjetividade. E a interpretação lacaniana da aquisição da linguagem pressupõe que no real há gozo.

Percebe-se, nesse debate com as teorias da aprendizagem, uma preocupação com a função do objeto $a$, como causa, na produção de conhecimento, como a causa em jogo no progresso da ciência e nos processos da compreensão. Para Lacan (1962-1963/2005), essa discussão possibilita a abordagem do "ponto de tensão" que há entre a Psicanálise e a Psicologia do Desenvolvimento, um dos pilares da Pedagogia e um dos principais alicerces das vertentes cognitivistas da Psicologia contemporânea. Ainda que percebido nas entrelinhas do Seminário 10, trata-se de um debate de grande importância, do qual podemos extrair a tentativa, por parte de Lacan, de demonstrar uma articulação entre o corpo e o saber - no contexto focalizado expresso nos termos "conhecimento" e "conceito". A essas passagens soma-se o comentário sobre a puberdade. Os termos "puberdade" e "conceito" só são conectados novamente no início do Seminário 12, Problemas cruciais para a psicanálise (Lacan, 1964-1965/n.d.), ${ }^{2}$ quando Lacan volta a debater com Piaget e finalmente nomeia o interlocutor com quem concorda quanto à questão dos conceitos na puberdade, Lev Vygotsky.

No início do Seminário 12, Lacan anuncia uma crítica às concepções de Piaget a propósito da relação entre inteligência e linguagem (aulas de 2, 9 e 16 de dezembro de 1964). Lacan parte da relação entre o significante e o sentido. Há uma perda que se produz cada vez que a linguagem tenta, num discurso, dar conta de si mesma. Para ele, não há metalinguagem, ponto principal da crítica à perspectiva piagetiana, que toma a linguagem como instrumento da inteligência, em uma concepção da inteligência como mecanismo de adaptação do organismo (Piaget, 1923/1999). O equívoco de Piaget, segundo Lacan, é considerar a linguagem um instrumento da inteligência, quando a linguagem é o mais inapropriado dos instrumentos, é o que embaraça, o que causa dificuldades à inteligência. Assim, a criança pequena que aprende a falar emprega mal as palavras. Há uma antecipação paradoxal de elementos da linguagem que só deveriam aparecer posteriormente. Segundo Lacan, esse mau uso da linguagem pelas crianças rechaça a tese de Piaget acerca da relação entre inteligência e linguagem.

Lacan propõe que "um significante pode servir para introduzir, na relação com o referente, alguma coisa

2 Seminário não publicado comercialmente. A edição usada é a versão publicada para circulação interna do Centro de Estudos Freudianos de Recife. que tem um nome, que se chama de conceito. E isso é uma relação de conotação. É, portanto, por intermédio da relação do significante com o referente que vemos surgir o significado" (Lacan, 1964-1965/n.d., p. 20). De acordo com $\mathrm{o}$ autor, Piaget negligencia esse referente, ao considerar o sujeito antes do discurso, e não efeito dele. Conforme a crítica lacaniana, Piaget desconhece a ordem que existe entre a linguagem e a lógica, na medida em que propõe uma primazia da lógica sobre a linguagem, interessando-se pela linguagem formal, gramatical, e não pela linguagem primitiva, a "linguagem materna", tocada pela libido. Ele se interessa pela linguagem que a criança aprende pela educação, enquanto Lacan chama a atenção para a linguagem como ordem simbólica, na qual a criança está mergulhada desde o início. Nesse mergulho, algo fica de fora da linguagem, algo do corpo, do real, que Lacan tenta, nesse momento, circunscrever pela noção de objeto $a$, a perda que se produz no nó de linguagem. Portanto, é preciso considerar a incidência desse objeto para se compreender o que está em jogo na aquisição da linguagem por uma criança.

Lacan concorda com outro teórico da aprendizagem, Vygotsky, que compreende a formação dos conceitos a partir da interação social, da cultura - concepção em consonância com a certeza lacaniana de que o inconsciente provém do laço social. Em breve comentário sobre as ideias desse pensador, esclarece-se a menção à puberdade expressa no Seminário 10. Naquele contexto, ao articular a puberdade à possibilidade de funcionamento do "verdadeiro conceito", Lacan faz alusão à concepção de Vygotsky segundo a qual o verdadeiro manejo do conceito só é atingido na puberdade. (Lacan, 1964-1965/n.d., pp. 33-34). Para Vygotsky, nessa fase há uma tomada de consciência da própria atividade mental em decorrência de uma relação especial com o objeto, o que permite a internalização do conceito e a compreensão de que ele faz parte de um sistema, possibilitando, assim, a abstração necessária para a generalização, diferenciação e formação dos "verdadeiros conceitos" (Vygotsky, 1934/1991). Referindo-se a essa teoria de Vygotsky, Lacan afirma: "mesmo um manejo rigoroso do conceito ... pode ser de qualquer sorte falacioso, e que o verdadeiro manejo do conceito não é atingido, diz ele, singularmente - e infelizmente sem tirar disso as consequências - senão na puberdade" (Lacan, 1964-1965/n.d., p. 34).

Ainda que esse comentário sobre a relação entre a puberdade e os conceitos apareça de forma pontual, ele traz todo um desdobramento teórico para esse seminário, dado que uma das grandes linhas de pensamento que percorrem todo o curso é justamente a articulação entre o saber, um dos problemas cruciais para a Psicanálise, e o corpo, lugar do púbis que se desvela na puberdade, da "maturação" do objeto $a$. Lacan se vale da discussão com esses autores para corroborar sua concepção de linguagem e para fundamentar uma elaboração de grande importância sobre o que ele chama de "problemas cruciais para a Psicanálise", um eixo teórico-topológico que amarra, no decorrer do Seminário 12, os termos "sujeito", "saber" e "sexo". Após 
esse seminário, esses termos são progressivamente elaborados e repensados no decorrer da trajetória do ensino lacaniano, o que possibilita que a conexão entre o saber e o corpo seja examinada através de uma perspectiva que situa o gozo no centro dessa problemática.

No Seminário 16, De um Outro ao outro (Lacan, 1968-1969/2008), Lacan aprimora sua concepção de objeto $a$ a partir da ideia marxista de mais-valia. Como o objeto $a$ é o que resta de gozo com a entrada na linguagem, ele é "mais-de-gozar", uma função de renúncia ao gozo sob o efeito do discurso. Com isso, o autor passa a pensar o saber como efeito dessa renúncia ao gozo, logo atrelado ao "maisde-gozar". Para ele, "toda manipulação possível da função do saber deve caber efetivamente na articulação ... do objeto a" (p. 196). Ao prosseguir nesse caminho, chega-se a uma definição do "desejo de saber", como essencial para a posição do sujeito em relação ao gozo sexual. "O ponto essencial da descoberta psicanalítica é o passo decisivo dado por Freud ao revelar a relação entre a curiosidade sexual e toda a ordem do saber, isto é, a junção do $a$ " (p. 312).

A partir desse breve percurso sobre a abordagem da puberdade nas obras de Freud e de Lacan, podemos apontar dois elementos nodais nessas teorizações: a questão do saber, expressa principalmente na problemática da latência - fase que frequentemente é retomada nas discussões que mencionam a puberdade por ambos os autores - e o problema do objeto, em sua articulação com o real do corpo - o objeto encontrado e reencontrado na dialética freudiana da sexualidade, e o objeto $a$, objeto de uma "maturação" na puberdade, na proposta lacaniana.

\section{A incidência sintomática do saber na adolescência}

A articulação proposta por Lacan entre a travessia da puberdade e o funcionamento do "verdadeiro conceito" por meio da "maturação do objeto $a$ " permite vislumbrar uma teoria lacaniana da puberdade: como evento no corpo detonador da adolescência, na puberdade está em jogo uma operação em que o real da sexualidade se relaciona com o saber. Como compreender essa operação de "engajamento no corpo"? De que maneira ela se relaciona com a concepção freudiana de latência, preâmbulo essencial ao evento da puberdade? Em que medida o debate entre Lacan e os autores do campo da Psicologia do Desenvolvimento e da Educação pode lançar luz sobre a sintomatologia contemporânea da adolescência, cada vez mais localizada na instituição escolar?

A clínica psicanalítica contemporânea indica que o sintoma na adolescência tem como principais facetas os seguintes elementos: a prevalência das respostas em ato seja na atuação violenta, na manipulação sintomática dos corpos ou nas adições -, o mal-estar no contexto escolar - incluindo toda a gama de impasses experimentados nas escolas hoje em dia, como o fracasso escolar, a decadência da figura do professor como ideal e o fenômeno do bullying - além da incidência da classificação diagnóstica, ou seja, os efeitos do discurso cientificista vigente sobre os jovens, com sua lógica classificatória e suas etiquetas diagnósticas. Esses elementos são particularmente comuns no discurso dos jovens que chegam ao consultório de Psicanálise, e muitas vezes estão inter-relacionados na determinação do sofrimento desses sujeitos.

Freud já reconhece a importância da escola para uma reflexão sobre a adolescência. Em um breve trabalho sobre o problema do suicídio de jovens escolares, ele ressalta que a escola deve conseguir mais do que não impelir seus alunos ao suicídio. "Ela deve lhes dar o desejo de viver e devia oferecer-lhes apoio e amparo numa época da vida em que as condições de seu desenvolvimento os compelem a afrouxar seus vínculos com a casa dos pais e com a família" (Freud, 1910/1996c, p. 243). O autor acrescenta que quando se lida com indivíduos imaturos, não se pode negar a eles "o direito de se demorarem em certos estágios do desenvolvimento e mesmo em alguns um pouco desagradáveis" (p. 244). Posteriormente, em uma homenagem à escola onde estudou dos 9 aos 17 anos, Freud (1914/1996e) afirma que entre a latência e a puberdade ocorre um desligamento do pai, um declínio da autoridade paterna. $\mathrm{O}$ vácuo que fica, ponto de desamparo para o jovem, vem ocupar a figura do professor, com toda a ambivalência que isso implica. Figura amada e odiada, nela é suposto o saber e é a ela que o jovem vai se referenciar em muitos momentos. $\mathrm{O}$ autor admite o fascínio pela personalidade dos mestres e que, para muitos, "os caminhos das ciências passavam apenas através de nossos professores" (p. 248), aludindo, assim, à incomensurável carga afetiva presente na transmissão e na apreensão do saber nesse período da vida.

Acerca das reflexões de Freud sobre a psicologia do escolar, Maria Celina Peixoto Lima (2012) ressalta que o autor postula a impossibilidade da aquisição de saber que não seja pelo Outro encarnado no mestre. Na escola contemporânea, porém, isso se torna extremamente problemático, visto que o mestre perde seu lugar, é desacreditado. Os jovens de hoje buscam um saber ao qual é possível ascender sem mediações do Outro, por meio da técnica e da profusão de informação. Diante dessa posição "autodidata" dos estudantes, a transmissão do saber perde seu valor nos dias de hoje. Em seu lugar, constatamos um verdadeiro "culto ao saber-objeto", como sublinha a autora. Sobre os adolescentes, ela acrescenta:

Navegando na internet, circulam em uma rede de informações sem autoria. O saber se apresenta em posição de objeto a ser assimilado, a ser devorado, consumido. Um saber por sua própria conta, sem valor de herança e que pretende dar provas de economia de um Pai. Como uma das figuras da errância adolescente, o internauta é o flaneur virtual. Retira-se das ruas e vagueia sem rumo pela tela. Acessa sítios, no entanto, sem demarcar seu lugar. Acede a saberes sem, no entanto, constituir filiações. (Lima, 2012, pp. 165-166) 
Se, no tempo de Freud, a escola já representa um lugar de suma importância na crise adolescente, atualmente, constatamos uma crise sem precedentes na própria educação, que padece do declínio da autoridade e do enfraquecimento generalizado dos referenciais simbólicos e ideais coletivos. A escola é o principal cenário para o laço social do adolescente, local onde os jovens passam grande parte de suas vidas, onde frequentemente têm lugar os conflitos, os encontros amorosos, os fracassos e os êxitos. Como palco privilegiado da cena adolescente, é geralmente na escola que a sintomatologia dos jovens ganha forma - não por superar a cena familiar em importância na genealogia do sintoma, mas por escancarar, a partir de sua própria incapacidade de acolher as diferenças e particularidades, o mal-estar de meninas e meninos às voltas com os impasses da travessia à vida adulta.

Paralelamente a esse declínio da autoridade na instituição escolar, constatamos, nos últimos anos, o aumento considerável no número de crianças e jovens inseridos em alguma categoria diagnóstica de transtorno mental, e grande parte desses "diagnósticos" tem origem nas dificuldades dos jovens nas escolas. Diante das "epidemias" que vêm se alastrando, tem sido frequente a chegada de adolescentes previamente classificados nos consultórios de Psicanálise. O sujeito chega ao tratamento munido de seu diagnóstico, ao qual está, geralmente, bastante identificado. Essa identificação a uma designação proveniente do discurso da ciência traz importantes consequências para seu tratamento. Independentemente da legitimidade ou não de tal diagnóstico, essa nomeação gera efeitos para o sujeito, sobretudo em um momento de vacilação subjetiva, de "afrouxamento de vínculos", como afirma Freud (1910/1996c).

Se na puberdade o corpo e o saber se enlaçam de forma estrutural, é possível pensar em saídas que considerem esse enlace em sua singularidade. Entretanto, na contemporaneidade, as saídas dos adolescentes têm se mostrado cada vez mais padronizadas, em movimentos de deriva, de desorientação em torno de objetos efêmeros estabelecidos pelo mercado, pelo discurso capitalista. A partir das perspectivas de Freud e de Lacan, concluímos que a metáfora edipiana fica inacabada, é interrompida por um tempo lacunar, ficando um resto a ser retomado na puberdade. Resta à puberdade a construção de uma amarração derradeira, capaz de dar sustentação à identificação. Contudo, em meio à crise de referenciais da atualidade, são escassos os ideais simbólicos disponíveis para os jovens se identificarem. Nesse vácuo, muitos ficam à deriva, e acabam encontrando "saídas" problemáticas, soluções provisórias e precárias em grupos caracterizados pela fragilidade do laço social. ${ }^{3}$

3 Como mostra o relato de um jovem em atendimento, cuja história de vida foi marcada pela violência, e que encontra um lugar onde se sente "em casa" em uma torcida organizada de um time de futebol. Ao ser perguntado sobre sua paixão pelo time ao qual a torcida se liga, o Atlético Mineiro, ele responde que "o time não importa" e conta que inclusive já havia sido membro da torcida arquirrival, a "máfia azul", ligada ao Cruzeiro. Explica a insólita situação ao afirmar que está na torcida "pelos manos", pelas brigas que planejam com os rivais, "pela adrenalina", e que o time "é o de menos". Notamos, aí, uma ausência do ideal, de qual-
Diante do imperativo de gozo e de toda a permissividade com a qual lidam crianças e jovens, latência e puberdade não são mais como antes, nos moldes do regime edípico clássico, como proposto por Freud. Essas modificações, em grande parte ainda insondáveis devido a sua atualidade, estão presentes na clínica e desafiam o psicanalista aos limites do diagnóstico e da técnica. Muitos adolescentes apresentam esses limites ao analista, de maneira mais explícita do que outros sujeitos, talvez por serem justamente aqueles que encarnam, de forma mais caricatural, os efeitos do discurso dominante. Assim, com preocupante frequência deparamos com jovens desnorteados, carentes de referenciais, visto que afrouxaram seus vínculos com o par parental, mas não constroem outros laços. Esses jovens muitas vezes estão entregues a atuações de risco.

A adolescência é o tempo em que o sujeito está mais propenso ao ato. Como define Lacan, a passagem ao ato é o mais radical recurso defensivo contra a angústia, afeto que é a tradução subjetiva do objeto $a$ (Lacan, 1962-1963/2005). A angústia é o afeto que mais acomete o sujeito adolescente, que, ao se deparar com o outro sexo, com o real da sexualidade, encontra-se desamparado, é remetido ao desamparo original de todo ser humano, à castração. É importante salientar que justamente em um trabalho sobre o suicídio, Freud (1910/1996c) já aponta a gravidade de uma abordagem apressada dessa fase da vida. O que percebemos hoje é o predomínio da pressa em se classificar os sujeitos, em se apresentar respostas quantitativas e soluções imediatas.

Diferentemente do modelo classificatório do DSM, ${ }^{4}$ tão bem acolhido por grande parte da instituição escolar atualmente, e das práticas terapêuticas que respondem à demanda por soluções rápidas, campos do saber que respondem ao mal-estar da contemporaneidade com uma epidemia de transtornos mentais e uma generalização dos tratamentos medicamentosos, a Psicanálise não tem respostas prontas. Todavia, não basta questionar essa compulsão classificatória e criticar a abrangência absurda da medicalização de crianças e jovens. Com Freud e Lacan, aprendemos que há um laço estreito entre o real do corpo e a relação do sujeito com o saber nesse período tão decisivo da vida que se dá na passagem da latência à puberdade - a ponte entre a infância e a vida adulta.

\section{Um saber sobre o impossível de saber}

A relação com o saber durante o período de latência e na passagem à puberdade tem um papel fundamental nas vicissitudes constitutivas do sujeito e no transcurso da adolescência. Com a chegada da puberdade, o jovem precisa lidar com o paradoxo de um saber que se apresenta

quer valor simbólico atribuível ao time de futebol, como nome que reúne seus torcedores por uma relação tradicionalmente transmitida entre gerações, por laços de família ou de pertencimento a certos grupos sociais. Ao invés disso, há a "adrenalina", como admite esse adolescente, que se sente "em casa" em um grupo que lhe permite participar de verdadeiras batalhas, nas brigas que as torcidas rivais programam.

4 Diagnostic and Statistical Manual of mental disorders, da Associação Americana de Psiquiatria (APA). 
no real do corpo. Trata-se de um saber sobre o impossível de saber, sobre a castração. Como Freud já indica, ocorre nesse momento o encontro do objeto que viabiliza a sexuação, o posicionamento do sujeito diante do outro sexo. Essa operação de sexuação envolve uma formulação singular de saber.

Lembrando que a relação entre saber e sexo é um dos pontos cruciais do ensino de Freud, Lacan afirma que "o sexo, em sua essência de diferença radical, permanece intocado e se recusa ao saber" (Lacan, 19641965/n.d., p. 351). É nisso que a pulsão epistemológica esbarra. O real que se apresenta na puberdade é esse impossível da relação sexual. Seguindo as pistas de Lacan a propósito da puberdade, inferimos que nesse momento algo permite que a relação do sujeito com o saber se modifique.

Para concluir, como exemplo de um caso clínico em que o problema do saber e das pesquisas sexuais se apresentam de forma particularmente clara, recorremos ao caso Dora (Freud, 1905/1996b), compreendido à luz do comentário de Lacan no seminário $O$ avesso da psicanálise (19691970/1992). Lacan aponta que o ponto do relativo fracasso desse tratamento se localiza em certa atribuição de saber por parte de Freud, que tenta abarcar o que se apresenta na análise com seu modelo edipiano e com o diagnóstico de histeria. Dora era uma histérica clássica, seu diagnóstico não está em discussão, mas é possível localizar o embaraço de Freud em relação ao caso em sua recusa a acolher o saber proveniente da paciente, impondo-lhe seu próprio saber de forma apressada.

Lembremos a importância da aquisição de conhecimento por parte de Dora, através de leituras "proibidas" e das relações, carregadas de ambivalência afetiva, com a sra. K. e com a governanta, mulheres que transmitem certos saberes à jovem. A questão do saber atravessa todo o caso clínico, aparecendo de maneira notável nos sonhos analisados por Freud - o segundo deles apresentando uma cena de desvelamento de um saber sobre a feminilidade, cena que é seguida por outra em que Dora se põe a abrir um livro e a ler (Freud, 1905/1996b). Esses elementos não passam despercebidos por Freud. Já Lacan (1969-1971/1992) examina detidamente esse fragmento de caso a partir da sua teoria dos quatro discursos, evidenciando as manobras do discurso do mestre em algumas intervenções de Freud, e a recusa da histérica, que denuncia as brechas do saber do mestre, sua castração. Tendo em vista essa leitura, destacamos os efeitos desse embaraço do analista, Freud, diante do saber que se apresenta no discurso de uma adolescente, Dora, um saber sobre o sexo, sobre o impossível da relação sexual e sobre a feminilidade. Nesse sentido, consideramos que o caso Dora é exemplar quanto ao embaraço diante da articulação entre o saber e o encontro do objeto na puberdade.

\section{The problem of knowledge in adolescence and the real of the puberty}

Abstract: This article proposes a reflection on the theme of adolescence in Psychoanalysis from a point of view that emphasizes the relation between knowledge, with its many implications, and puberty, as the real of the body that erupts in this age group. We present points of the works of Freud and Lacan supporting this articulation and some works of contemporary authors about this problem.

Keywords: adolescence, puberty, knowledge, object.

\section{Le problème du savoir à l'adolescence et le réel de la puberté}

Résumé: Cet article propose une investigation sur le thème de l'adolescence dans la Psychanalyse, en focalisant la relation entre le savoir et le corps comme une opération fondamentale pendent l'adolescence. On présente cette question chez Freud et chez Lacan, et aussi d'autres discussions des auteurs contemporains sur ce problématique.

Mots-clés: adolescence, puberté, savoir, objet.

\section{El problema del saber en la adolescencia y lo real de la pubertad}

Resumen: Este artículo propone una reflexión sobre el tema de la adolescencia en el psicoanálisis, a partir de un punto de vista que destaca la vinculación entre el saber, con sus muchas implicaciones, y la pubertad, como el real del cuerpo que se manifiesta en este momento de la vida. Presentamos trechos de las obras de Freud y de Lacan que apoyan esta vinculación, así como una discusión de autores contemporáneos que abordan esta problemática.

Palabras clave: adolescencia, pubertad, saber, objeto. 


\section{Referências}

Dunker, C. I. L. (2006). A angústia e as paixões da alma. In N. Leite, (Org.). Corpolinguagem - Angústia: o afeto que não engana (pp. 305-316). Campinas, SP: Mercado das Letras.

Freud, S. (1996a). Três ensaios sobre a teoria da sexualidade. In S. Freud, Edição standard brasileira das obras psicológicas completas de Sigmund Freud (Vol. 7, pp. 119-229). Rio de Janeiro, RJ: Imago. (Trabalho original publicado em 1905)

Freud, S. (1996b). Fragmento da análise de um caso de histeria. In S. Freud, Edição standard brasileira das obras psicológicas completas de Sigmund Freud (Vol. 7, pp. 15-116). Rio de Janeiro, RJ: Imago. (Trabalho original publicado em 1905)

Freud, S. (1996c). Contribuições para uma discussão acerca do suicídio. In S. Freud, Edição standard brasileira das obras psicológicas completas de Sigmund Freud (Vol. 11, pp. 243-244). Rio de Janeiro, RJ: Imago (Trabalho original publicado em 1910)

Freud, S. (1996d). Formulações sobre os dois princípios do funcionamento mental. In S. Freud, Edição standard brasileira das obras psicológicas completas de Sigmund Freud (Vol. 12, pp. 233-244). Rio de Janeiro, RJ: Imago. (Trabalho original publicado em 1911)

Freud, S. (1996e). Algumas reflexões para a psicologia do escolar. In S. Freud, Edição standard brasileira das obras psicológicas completas de Sigmund Freud (Vol. 13, pp. 246-250). Rio de Janeiro, RJ: Imago. (Trabalho original publicado em 1914)

Freud, S. (1996f). Uma criança é espancada: uma contribuição ao estudo da origem das perversões sexuais. In S. Freud, Edição standard brasileira das obras psicológicas completas de Sigmund Freud (Vol. 17, pp. 193-218). Rio de Janeiro, RJ: Imago. (Trabalho original publicado em 1919)

Freud, S. (1996g) O ego e o id. In S. Freud, Edição standard brasileira das obras psicológicas completas de Sigmund Freud (Vol. 17, pp. 15-75). Rio de Janeiro, RJ: Imago. (Trabalho original publicado em 1923)

Freud, S. (1996h) A organização genital infantil. In S. Freud, Edição standard brasileira das obras psicológicas completas de Sigmund Freud (Vol. 19, pp. 155-161). Rio de Janeiro, RJ: Imago. (Trabalho original publicado em 1923)

Freud, S. (1996i). A dissolução do complexo de Édipo. In S. Freud, Edição standard brasileira das obras psicológicas completas de Sigmund Freud (Vol. 19, pp. 191-199). Rio de Janeiro, RJ: Imago. (Trabalho original publicado em 1924)

Freud, S. (1996j). Inibições, sintomas e ansiedade. In S. Freud, Edição standard brasileira das obras psicológicas completas de Sigmund Freud (Vol. 20, pp. 81-171). Rio de Janeiro, RJ: Imago. (Trabalho original publicado em 1926).

Lacan, J. (1992). O seminário. Livro 17: o avesso da psicanálise (A. Roitman, trad.). Rio de Janeiro, RJ: Jorge
Zahar. (Trabalho original publicado em 1969-1970)

Lacan, J. (1995). O seminário. Livro 4: a relação de objeto (D. D. Estrada, trad.). Rio de Janeiro, RJ: Jorge Zahar. (Trabalho original publicado em 1956-1957)

Lacan, J. (1999). O seminário. Livro 5: as formações do inconsciente (V. Ribeiro, trad.). Rio de Janeiro, RJ: Jorge Zahar. (Trabalho original publicado em 1957-1958)

Lacan, J. (2003a). Os complexos familiares na formação do indivíduo. In J. Lacan, Outros escritos (V. Ribeiro, trad., pp. 29-90). Rio de Janeiro, RJ: Jorge Zahar. (Trabalho original publicado em 1938)

Lacan, J. (2003b). Prefácio a "O despertar da primavera". In J. Lacan, Outros escritos (V. Ribeiro, trad., pp. 557559). Rio de Janeiro, RJ: Jorge Zahar. (Trabalho original publicado em 1974)

Lacan, J. (2005). O seminário. Livro 10: a angústia (V. Ribeiro, trad.). Rio de Janeiro, RJ: Jorge Zahar. (Trabalho original publicado em 1962-1963)

Lacan, J. (2008). O seminário. Livro 16: de um Outro ao outro (V. Ribeiro, trad.). Rio de Janeiro, RJ: Jorge Zahar. (Trabalho original publicado em 1968-1969)

Lacan, J. ([s.d]). O seminário. Livro 12: problemas cruciais para a Psicanálise (L. P. Fonseca, trad.). Publicação para circulação interna do Centro de Estudos Freudianos de Recife. (Trabalho original publicado em 1964-1965)

Lima, M. C. P. (2012). O declínio do mestre e sua relação com o saber na adolescência. In R. Gurski, M. D. Rosa, M. C. Poli (Orgs.), Debates sobre a adolescência contemporânea e o laço social (pp. 161-170). Curitiba, PR: Juruá.

Miller, J.-A. (2005, maio). Introdução à leitura do seminário 10 da angústia de Jacques Lacan (V. Ribeiro, trad.). Opção Lacaniana, 43, 7-91.

Piaget, J. (1999). O pensamento e a linguagem na criança. São Paulo, SP: Martins Fontes. (Trabalho original publicado em 1923)

Santiago, J. (2010). Lacan y el grifo de Piaget: sobre el objetocausa del deseo en el Seminario 10 de Jacques Lacan. In E. Berenguer, M. Fernández Blanco, M. Bassols, N. Guerrero de Medina, J. Fernando Velásquez, J. Santiago, \& G. Brodsky, La angustia en Freud y Lacan: cuerpo, significante y afecto. (Vol. 2, pp. 143-157). Bogotá: Colômbia: NEL Bogotá.

Vygotsky, L. (1991). Pensamento e linguagem (3a ed.) São Paulo, SP: Martins Fontes. (Trabalho original publicado em 1934)

Wedekind, F. (1973). O despertar da primavera. Lisboa: Portugal: Estampa. (Trabalho original publicado em 1891)
Recebido: $25 / 10 / 2013$

Revisado: 02/04/2014

Aceito: 04/09/2014 